\title{
Study of Criticality Safety and Neutronic Performance for a 348-Fuel-Pin Ghana Research Reactor-1 LEU Core Using MCNP Code
}

\author{
Henry Cecil Odoi ${ }^{1}{ }^{*}$, Edward H. K. Akaho ${ }^{1}$, Sunday A. Jonah ${ }^{2}$, Rex Gyeabour Abrefah ${ }^{1}$, \\ Viva Y. Ibrahim ${ }^{2}$ \\ ${ }^{1}$ National Nuclear Research Institute, Ghana Atomic Energy Commission, Accra, Ghana \\ ${ }^{2}$ Centre for Energy Research and Training, Ahmadu Bello University, Zaria, Nigeria \\ Email: ${ }^{\text {hencilod@gmail.com }}$
}

Received August 27, 2013; revised October 7, 2013; accepted October 29, 2013

Copyright (C) 2014 Henry Cecil Odoi et al. This is an open access article distributed under the Creative Commons Attribution License, which permits unrestricted use, distribution, and reproduction in any medium, provided the original work is properly cited. In accordance of the Creative Commons Attribution License all Copyrights (C) 2014 are reserved for SCIRP and the owner of the intellectual property Henry Cecil Odoi et al. All Copyright (C 2014 are guarded by law and by SCIRP as a guardian.

\section{ABSTRACT}

The National Nuclear Research Institute of the Ghana Atomic Energy Commission is undertaking steps to convert the Ghana Research Reactor-1 from HEU Core to LEU. The proposed LEU core consists of $12.5 \%$ enriched $\mathrm{UO}_{2}$ fuel elements clad in Zircaloy-4 alloy. This is done in collaboration with Reduced Enrichment for Research and Test Reactor. The versatile MCNP code was used to analyse the neutronics parameters given in the SAR of HEU core, thereby characterizing the core. Subsequently, the LEU core was indentified with necessary changes to the HEU MCNP model. It was ascertained that the reactivity for the LEU core with the same number of fuel pins as the HEU was inadequate, hence the fuel pins were increased from 344 to 348 . The neutron flux at the irradiation sites was found to be below the nominal value at full power for the LEU and hence the nominal power was increased to $34 \mathrm{~kW}$ for a nominal flux value of $1 \times 10^{12} \mathrm{n} / \mathrm{cm}^{2} \cdot \mathrm{s}$. The parameters investigated for the HEU and LEU are shown in this paper.

\section{KEYWORDS}

Neutronics; Multiplication Factor; Reactivity; Neutron Flux

\section{Introduction}

According to the IAEA Research Reactor Database (RRDB), 735 research reactors have been constructed around the world for civilian applications. On the basis of the RRDB, 244 research reactors are currently in operation, 148 are shut down and 306 have been decommissioned, whiles others are under temporary shutdown [1]. One type of such research reactors in operation is the Miniature Neutron Source Reactors (MNSR). Ghana's MNSR was obtained under a Project Supply Agreement between the International Atomic Energy Agency (IAEA), the China Institute of Atomic Energy (CIAE) and the Government of Ghana in 1994 [2]. The reactor was assembled between October and December 1994 and it went critical in 17th December, 1994 [3]. Subsequently,

"Corresponding author. it was commissioned on 15th March 1995. The National Nuclear Research Institute of the Ghana Atomic Energy Commission is undertaking steps to convert the Ghana Research Reactor-1 from HEU Core to LEU [4]. This is in response to the global trend in converting research and test reactors from the use of high enriched uranium to low enriched uranium in civil nuclear application.

The objective of this study is to design an LEU core with similar operational capabilities as the original HEU core and with acceptable safety margins under both normal and accident conditions. In order to provide comparisons between the proposed LEU core and the initial GHARR-1 HEU core, thorough analyses were performed for both cores. The proposed LEU core consists of $12.5 \%$ enriched $\mathrm{UO}_{2}$ fuel elements clad in Zircaloy-4 alloy. The control element of the control rod material will remain unchanged but the diameter of the absorber material 
would increase, leaving the diameter of the control rod unchanged.

In the following sections of this document, it is revealed that throughout the lifetime of the proposed LEU core:

1) The shutdown margin meets Technical Specification limits.

2) Reactivity coefficients meet required limits and are comparable to the existing HEU core.

3) There will be no tradeoff in the thermal neutron fluxes in the experimental channels. This will be achieved by increasing the power of the LEU core by $13 \%$.

\section{Neutronic Analysis}

MNSR reactors are simple in design and structure. As per all types of reactor, neutronics analysis of MNSRs can be done with reactor codes based on both deterministic and Monte Carlo approaches. In the past, deterministic methods and codes have been employed for reactor analysis of the Ghana MNSR [5].

In recent times, however, the Monte Carlo approach to reactor analysis has been included. In particular, multipurpose Monte Carlo particle transport codes generally have the capability to model and treat different complicated geometries in 3-D and also simulate the transport behavior of different particles and nuclear interaction processes. Good and accurate modeling of the different zones and diverse geometries of the MNSR reactor is important for realizing good neutronics, particle transport simulation, and physics analysis. For these reasons, the versatile and widely utilized MCNP code particle transport code was employed to develop a 3-D Monte Carlo model for MNSR for particle transport simulation and neutronic analysis of MNSR reactors.

\section{Monte Carlo Model for GHARR-1}

Before The Monte Carlo method has been in used for almost sixty years to solve radiation transport problems in high energy physics, nuclear reactor analysis, radiation shielding, medical imaging, etc [6]. Individual particles histories are simulated using random numbers, highly accurate representations of particle interaction probabilities, and exact models of three dimensional problem geometry. Monte Carlo methods are sometimes the only viably methods for analyzing complex, demanding particle transport problems.

The MCNP5 transport code [7] was used to perform the Monte Carlo calculations. Nuclear data for fissile and non-fissile isotopes associated with materials (fuel and clad, coolant, moderator, control rod and clad, reflectors, 5 structural components) of the physical model was chosen from ENDF/B-VI nuclear data libraries. The special
$\mathrm{S}(\alpha \beta)$ scattering feature was applied in the nuclear model to treat thermal scattering in beryllium and hydrogen in light water for the reflector material and water regions respectively of the GHARR-1 Monte Carlo model. Neutronics analyses were performed using a condensed 3-group neutron energy structure: up $0.625 \mathrm{eV}$ for thermal neutrons, $<8.21 \mathrm{eV}$ for epithermal neutrons and up to $20 \mathrm{MeV}$ for fast neutrons.

All this were done to establish the deck for the HEU core and after it been ascertained that results compare very well with experimental data, the necessary modifications were made to acquire the LEU model for the core conversion exercise. Comparison of the parameters of the two cores is shown in Table 1.

The MCNP plots of the GHARR-1 core configuration and the vertical cross-section are shown in other journals; Abrefah et al. 2012 [8], Odoi et al., 2011 [9].

Preliminary calculations were performed to make the fission source converge from an initial guess distribution with arbitrary but uniform set of points in the fuel regions to estimate nuclear criticality, keff, excess reactivity, pex and control rod worth, using the KCODE option with rod withdrawn and inserted as the case may be. In this work, the final runs for the KCODE involved typi-

Table 1. Comparison of key parameters for reference GHARR-1 HEU and LEU cores.

\begin{tabular}{|c|c|c|}
\hline Key Parameters & HEU & LEU \\
\hline Fuel Meat & $\mathrm{U}-\mathrm{Al}_{4}$ & $\mathrm{UO}_{2}$ \\
\hline U-235 Total Core Loading, g & $\sim 998$ & $\sim 1358$ \\
\hline U-235 Enrichment, wt\% & 90.2 & 12.5 \\
\hline U-234 content, wt\% & 1.0 & 0.2 \\
\hline U-236 content, wt $\%$ & 0.5 & 0.25 \\
\hline Density of Meat, $\mathrm{g} / \mathrm{cm}^{3}$ & 3.456 & 10.6 \\
\hline Meat Diameter, mm & 4.3 & 4.3 \\
\hline Cladding Diameter, mm & 5.5 & 5.5 \\
\hline Thickness of He Gap, mm & None & 0.05 \\
\hline Cladding Material & Al-303-1 & Zirc-4 \\
\hline Number of Fuel Rods & 344 & 348 \\
\hline Material for Grid Plates & LT-21 & Zirc-4 \\
\hline Top Shim Tray (not modeled) & LT-21 & LT-21 \\
\hline Number of Dummy Elements & 6 & 2 \\
\hline Material for Dummy Elements & Al-303-1 & Zirc-4 \\
\hline Number of Tie Rods & 4 & 4 \\
\hline Material for Tie Rods & Al-303-1 & Zirc-4 \\
\hline Adjuster Guide Tubes & 4 & 4 \\
\hline
\end{tabular}


cally 30 settle cycles followed by 800 cycles of 500,000 histories. Power iteration for Monte Carlo criticality calculation of the mean value of $\mathrm{k}$ is shown in Figure 1 .

\section{Results and Discussion}

The excess reactivity, $\rho$ ex was estimated by running the input with control rod withdrawn using Equation (1) [11].

$$
\rho \mathrm{ex}=\left(K_{\text {eff }}-1\right) /\left(K_{\text {eff }}\right)
$$

The reactivity worth of the control rod was obtained using the relation

Control rod worth $=\rho \mathrm{ex}+$ shutdown margin,

where the shutdown margin is the negative reactivity the core present when the control rod is fully inserted.

\subsection{Criticality Results}

The core excess reactivity calculated for the LEU UO2 fuel with 344 fuel pins was below the $3 \mathrm{mk}$ and therefore it is insufficient for the design of MNSR core. Hence the number of pins was increased to 348 to achieve the design reactivity of MNSR which is between $3.5 \mathrm{mk}$ and $4.0 \mathrm{mk}$. This is evident in Table 2.

The Criticality results for the HEU and 348-pin LEU cores are shown in Table 3. The Multiplication factors, $K_{\text {eff, }}$ and of course the reactivities are quite comparable and also compare well with values stated in the HEU SAR. The delayed neutron fractions for the two cores as estimated by Monte Carlo N Particle Code are 3.3\% and $3.9 \%$ higher than MNSR manufacturer's quoted value of 0.00808 [12] respectively. Nevertheless, the two com-

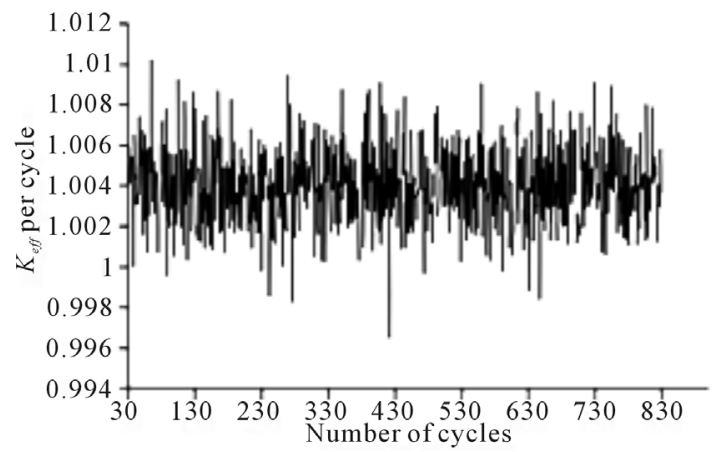

Figure 1. Power iteration for Monte Carlo critical calculation of mean value of $K_{\text {eff }}$ [10].

Table 2. Comparison of Reactivities for various cores.

\begin{tabular}{ccc}
\hline Fuel/No. of Pins & $K_{\text {eff }}$ & Reactivity, mk \\
\hline HEU; 344 pins & $1.00375 \pm 0.00005$ & $3.74 \pm 0.05$ \\
LEU; 344 pins & $1.00289 \pm 0.00006$ & $2.88 \pm 0.05$ \\
LEU; 348 pins & $1.00385 \pm 0.00004$ & $3.84 \pm 0.04$ \\
\hline
\end{tabular}

pares well with the delay neutron fraction of 0.00857 reported for NIRR-1 [Jonah, S. A. et al., May 2008].

The design control rod worth of the reactor is $6.8 \mathrm{mk}$ and the shutdown margin is $3.0 \mathrm{mk}$ for maintaining the reactor in safe shutdown conditions. The total cold excess reactivity to be compensated is about $4.0 \mathrm{mk}$ by the control rod [13]. The Monte Carlo calculation of the control rod worth is about $10.5 \%$ more for the HEU core. Both the HEU and LEU cores have shutdown margin close to $3 \mathrm{mk}$.

\subsection{Integral and Differential Control Rod Worth}

The exact effect of control rods on reactivity can be determined experimentally. For example, a control rod can be withdrawn in small increments, such as $1 \mathrm{~cm}$, and the change in reactivity can be determined following each increment of withdrawal. By plotting the resulting reactivity versus the rod position, a graph obtained for both cores are shown in Figure 2. The graph depicts integral control rod worth over the full range of withdrawal. The integral control rod worth is the total reactivity worth of the rod at that particular degree of withdrawal and is usually defined to be the greatest when the rod is fully withdrawn.

The integral rod worth at a given withdrawal is merely the summation of the entire differential rod worth up to that point of withdrawal. It is also the area under the differential rod worth curve at any given withdrawal position. The highest differential control rod worth occurred below the centre of the core.

\subsection{Flux Distributions}

Measurement of neutron flux and neutron energy spectrum parameters in the inner irradiation sites can be utilised to determine linearity, repeatability and stability of the neutron measurement system, which includes detectors and secondary instrument. The LB1120 miniature fission chamber is employed as a neutron detector for the reactor. It has a small size and can be put into the side annulus. In the linear range of this detector the absolute neutron flux over 4 - 5 decades could be measured with both gold and manganese foils [13]. The average flux distributions in the inner irradiation channels, outer irrdiation channels and that of the fission chambers are shown in Figures 3-5 respectively. The centre of the core is equidistant from the inner irradiation channels and the fission chamber which houses the device used in measuring the neutron flux experimentally. The various graphs follow the same pattern and also depict the reduction in the thermal neutron flux of the LEU core at 30 $\mathrm{kW}$.

In order not to compromise the thermal neutron flux especially in the inner irradiation channel, the power of 
the LEU core is increased by $13 \%$ to recompense the fall in flux at $30 \mathrm{~kW}$. This is base on the ratio of the average thermal neutron flux in the inner irradiation channel at 30 $\mathrm{kW}$ of the LEU core to that of the HEU core. Hence the power for LEU core is increase to $34 \mathrm{~kW}$.

This is to normalize the thermal neutron flux ratio in the inner irradiation channels to unity. So the two profiles of the thermal flux are almost completely superimposed on the other as observed in Figure 6. The effects of the increase in power of the LEU core on the neutron fluxes in the other locations are shown in Figures 7 and 8.

The peak fluxes in the inner irradiation channels are shown in Table 4 . The decreases in the peak fluxes as a result of the core conversion are in the range of $10 \%$ to $13 \%$ with an average of about $11 \%$. This supports the increase in power of the LEU core by about $13 \%$ to compensate for the decrease in neutron flux estimated.

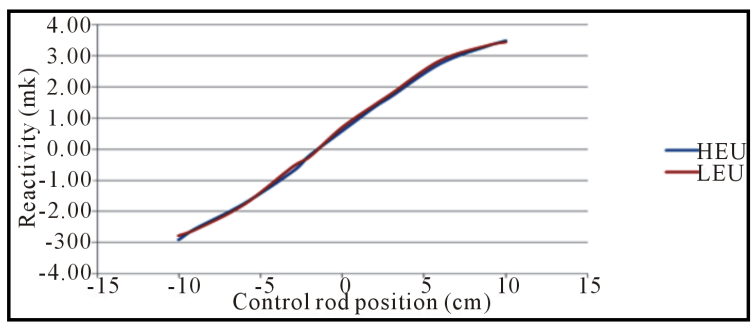

Figure 2. The integral control rod curve.

Table 3. Comparison of criticality results for HEU and LEU.

\begin{tabular}{|c|c|c|c|}
\hline Criticality Result & HEU SAR & HEU & LEU \\
\hline$K_{e f f}-$ Control rod completely withdrawn & - & $1.00375 \pm 0.00005$ & $1.00385 \pm 0.00004$ \\
\hline Core excess reactivity, mk & 4.0 & $3.74 \pm 0.05$ & $3.84 \pm 0.04$ \\
\hline Delayed neutron fraction $\left(\beta_{e f f}\right), 10^{3}$ & 8.5 & $8.347 \pm 0.0641$ & $8.395 \pm 0.0566$ \\
\hline Prompt Neutron lifetime $(\Lambda), \mathrm{s}$ & $8.52 \times 10^{-5}$ & $(8.46 \pm 0.06) \times 10^{-5}$ & $(7.39 \pm 0.06) \times 10^{-5}$ \\
\hline Control rod worth, mk & 6.80 & $6.95 \pm 0.018$ & $6.74 \pm 0.017$ \\
\hline Shutdown margin, mk & 3.0 & $3.21 \pm 0.012$ & $2.87 \pm 0.011$ \\
\hline
\end{tabular}

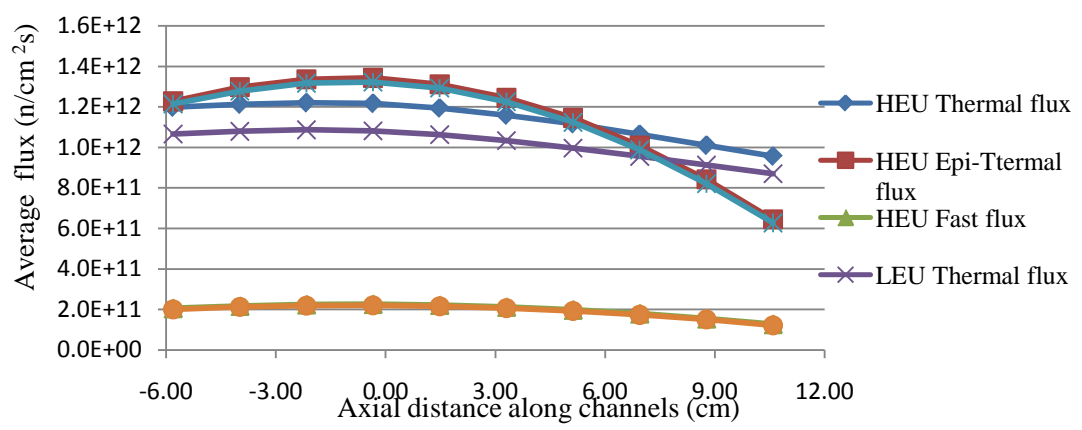

Figure 3. Comparison of average flux distribution in the inner irradiation channel at $30 \mathrm{~kW}$.

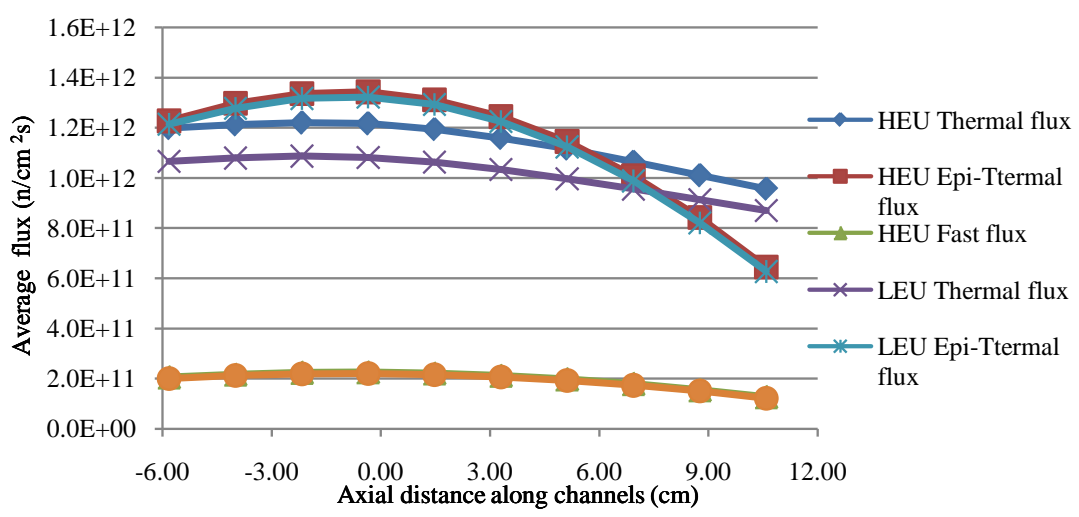

Figure 4. Comparison of flux distribution in the fission chamber at $30 \mathrm{~kW}$. 


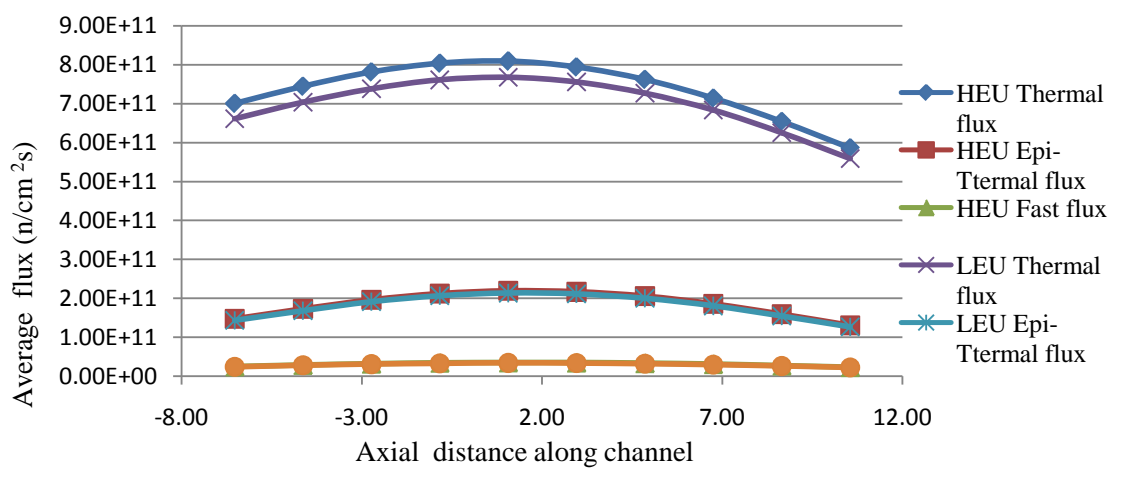

Figure 5. Comparison of average flux distribution in outer irradiation channel at $30 \mathrm{~kW}$.

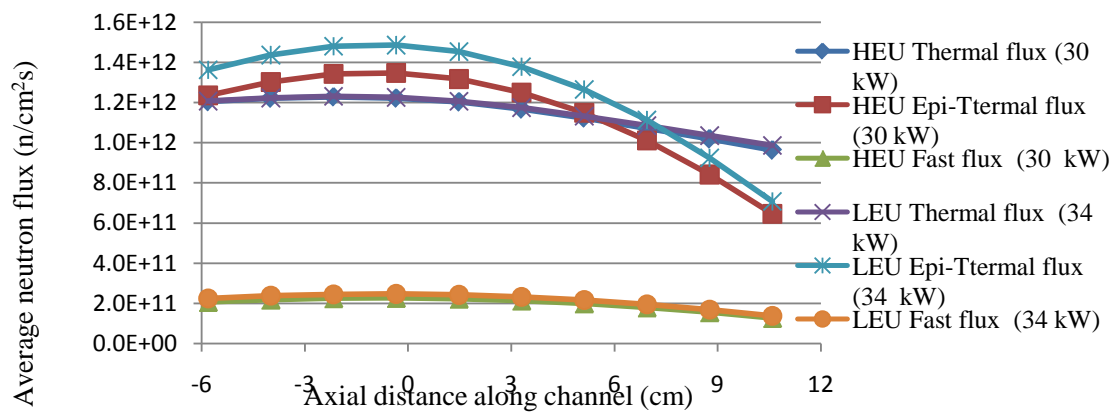

Figure 6. Comparison of average flux distribution in inner irradiation channel at nominal powers.

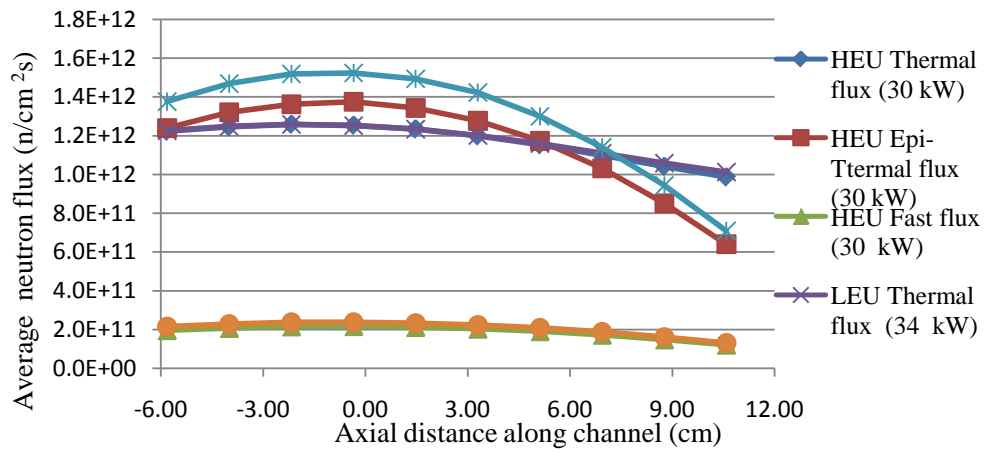

Figure 7. Comparison of average flux distribution in fission chamber at nominal powers.

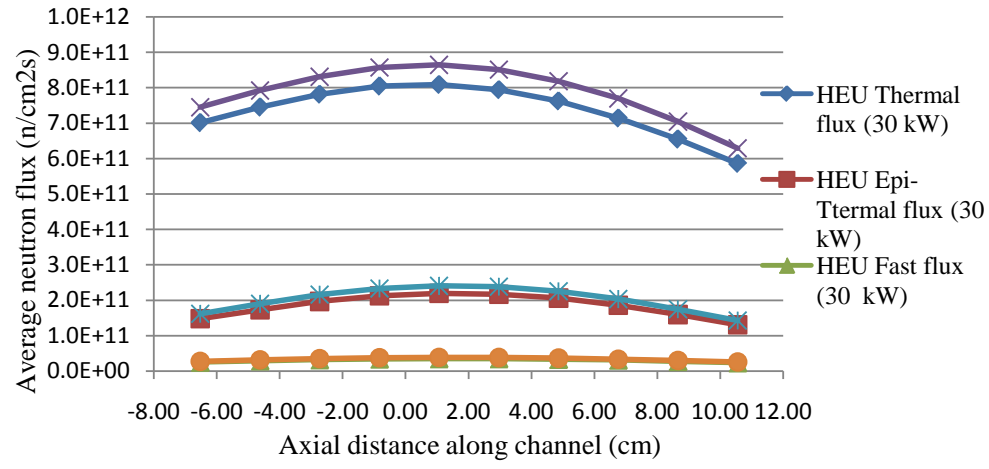

Figure 8. Comparison of average flux distribution in outer irradiation channel at nominal powers.

The MCNP5/MCNPX code is capable of computing the axial power profiles of the fuel pins in the core. Compar- ison of peak power profile for the two cores is shown in Figure 9; the axial power profile of the LEU core at 34 


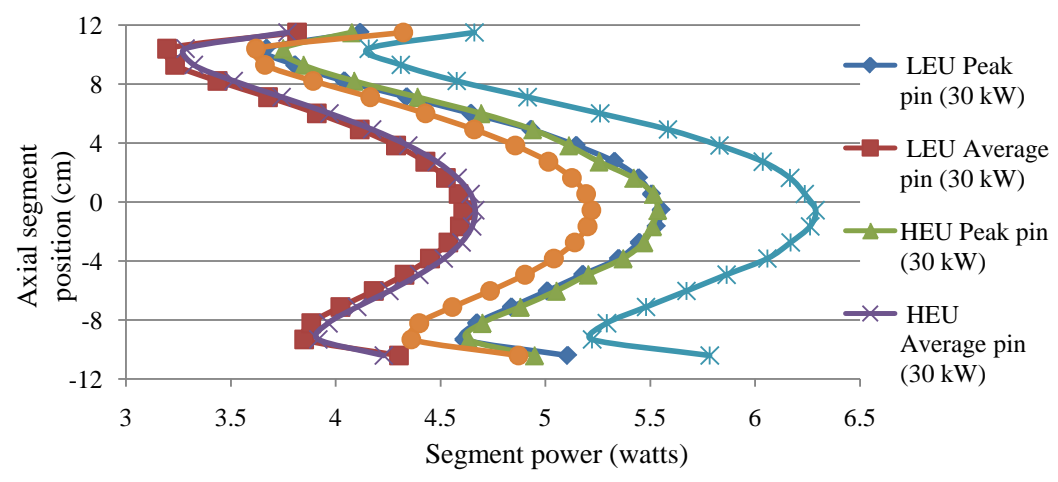

Figure 9. Peak power pin axial profile (21 segments).

Table 4. Peak flux in the inner irradiation channels $\left(\mathbf{n} / \mathbf{c m}^{2} \mathbf{s}\right)$.

\begin{tabular}{|c|c|c|c|}
\hline Channels (MCNP) & HEU 30 kW (n/cm²s) & LEU 30 kW (n/cm²s) & LEU 34 kW (n/cm²s) \\
\hline Cell 971 & $(1.220 \pm 0.0018) \mathrm{E}+12$ & $(1.087 \pm 0.0017) \mathrm{E}+12$ & $(1.223 \pm 0.0017) \mathrm{E}+12$ \\
\hline Cell 933 & $(1.231 \pm 0.0018) \mathrm{E}+12$ & $(1.091 \pm 0.0018) \mathrm{E}+12$ & $(1.228 \pm 0.0017) \mathrm{E}+12$ \\
\hline Cell 935 & $(1.217 \pm 0.0018) \mathrm{E}+12$ & $(1.100 \pm 0.0018) E+12$ & $(1.238 \pm 0.0018) \mathrm{E}+12$ \\
\hline Cell 937 & $(1.253 \pm 0.0018) \mathrm{E}+12$ & $(1.098 \pm 0.0018) \mathrm{E}+12$ & $(1.236 \pm 0.0018) \mathrm{E}+12$ \\
\hline Cell 939 & $(1.221 \pm 0.0018) \mathrm{E}+12$ & $(1.097 \pm 0.0018) E+12$ & $(1.235 \pm 0.0018) \mathrm{E}+12$ \\
\hline Average & $(1.228 \pm 0.0006) \mathrm{E}+12$ & $(1.095 \pm 0.0018) \mathrm{E}+12$ & $(1.232 \pm 0.0018) \mathrm{E}+12$ \\
\hline
\end{tabular}

$\mathrm{kW}$ is also included. The axial power profiles are important for thermal hydraulic analyses, and thermal hydraulic codes such as PARET and PLTEMP require both peak and average power profile for computation of safety margins, transients, etc.

\section{Conclusion}

Ghana is committed to ensuring the success of the IAEA-RERTR HEU-LEU conversion program and $12.5 \%$ enriched $\mathrm{UO}_{2}$ has been chosen as fuel for LEU Core. For core excess reactivity of $4 \mathrm{mK}, 348$ fuel pins would be appropriate for the GHARR-1 LEU core. Results indicate that flux distribution in the inner irradiation channels will not be compromised, if the power of LEU core is increased to $34 \mathrm{~kW}$.

\section{Acknowledgements}

The authors acknowledge, with gratitude, the financial support of International Atomic Energy Agency for the award of Research Contract Number GHA/13946. The authors also appreciate fellowships sponsored by US Department of Energy. We particularly thank the staff of Nuclear Engineering Section of Argonne National Laboratory for hosting of fellowships and the importance they assigned to this project. We also appreciate the contributions made by the trio, Robert B. M. Sogbadji, Emmanuel Ampomah-Amoako and Sylvester A. Birikorang, all of Ghana Atomic Energy Commission.

\section{REFERENCES}

[1] International Atomic Energy Agency, "Research Reactors Database," 2013.

http://nucleus.iaea.org/RRDB/RR/ReactorSearch.aspx?filt $\underline{\mathrm{er}=0}$

[2] International Atomic Energy Agency Information Circular , "Project and Supply Agreement," INCIRC/468, April, 1995.

[3] E. H. K. Akaho, B. T. Maaku, S. Anim-Sampong, L. Yizheng and Z. Wuqin, "On-Site Critical and Zero Power Experiments for Start-up of GHARR-1," GAEC-NNRIRT-22, Kwabenya, Ghana, 1995.

[4] E. Ampomah-Amoako et al., "Storage and Transport of Spent Fuel from Ghana Research Reactor-1 for conversion from HEU to LEU," 32nd International Meeting on Reduce Enrichment for Research and Test Reactors, Lisbon, 10-14 October 2010.

http://www.rertr.anl.gov/RERTR32/index.shtml

[5] W. L. Woodruff, "Evaluation and Selection of Hot Channel (Peaking) Factors for Research Reactors Applicaiton," CONF-8709189-2, Intl Mtg. Reduced Enrichment for Research and Test Reactors (RERTR), Buenos Aires, September 1987.

[6] W. Gudowski, "Monte Carlo Methods for Accelerator-Driven Systems (SMR/1326-8)," Workshop on Hybrid Nuclear Systems for Energy Production, Utilization of Actnides and Transmutation of Long-Lived Radioactive 
Waste, Trieste, 3-7 September 2001.

[7] J. F. Briesmeister, "MCNP-A General Monte Carlo NParticle Transport Code,” Version 4C-LA-13709.2000 7.

[8] R. G. Abrefah, H. C. Odoi, E. Ampomah-Amoako and E. Mensimah, "Investigation into the Effects of Zircaloy-4 on the Neutronics of Low Enriched Uranium MNSR Core,” Progress in Nuclear Energy, Vol. 54, No. 1, 2012, pp. 5-10.

www.elsevier.com/locate/pnucene

[9] H. C. Odoi, et al., "Investigative Studies on Effect of Reflector Thickness on the Performance of Low Enriched Uranium-Fuelled MNSRs,” Nuclear Engineering and Design, Vol. 241, No. 8, 2011, pp. 2909-2915. www.elsevier.com/locate/nucengdes http://dx.doi.org/10.1016/j.nucengdes.2011.05.019
[10] Y. V. Ibrahim, H. C. Odoi, R. L. Njinga, M. O. Odeleye and S. A. Jonah, "Monte Carlo Simulation of Additional Safety Control Rod for Commercial MNSR to Enhance safety," Annals of Nuclear Energy, Vol. 44, 2012, pp. 7175. www.elsevier.com/locate/anucene http://dx.doi.org/doi:10.1016/j.anucene.2012.01.008

[11] J. Duderstadt and L. J. Hamilton, "Nuclear Reactor Physics,” John Wiley and Sons Inc., Hoboken, 1976.

[12] G. Chenzhan, "The Effect of Xenon Poisoning on MNSR Operation,” 1991.

[13] E. H. K. Akaho, S. Anim-Sampong, G. Emi-Reynolds, D. N. A. Dodoo-Amoo and T. B. Maaku, "Safety Analysis Report for Ghana Research Reactor-1,” GEAC-NNRIRT-26, March 1995. 